\title{
An Overview on Women’s Leadership Issues in Jordan
}

\author{
Faraj Radwan Zubaidi (Corresponding author) \\ College of Business, University Utara Malaysia (UUM) \\ 06010 Sintok, Kedah, Malaysia \\ Tel: 60-12-977-0905Ｅ-mail: zbaidi@yahoo.com \\ Nabiha.S. Mehdi Al-Sammerai \\ Academy of Islamic Studies, University of Malaya (UM) \\ 50603 Kuala Lumpur, Malaysia \\ Tel: 96-89-805-0608Ｅ-mail: nabiha178@yahoo.com, nabiha@um.edu.my \\ Fais Ahmad \\ College of Business, University Utara Malaysia (UUM) \\ 06010 Sintok, Kedah, Malaysia \\ Tel: 60-13-428-9190Ｅ-mail: fais@uum.edu.my
}

Received: October 23, 2010 Accepted: January 10, 2011 doi:10.5539/jpl.v4n2p67

\begin{abstract}
The success and efficiency of leadership depends on managerial position of what leader possesses of personal characteristics, education qualification and professional expertise. Nowadays, the leadership of woman is become more essential in the developing process for the civilized societies as a man's colleague in managing companies. However, woman in some societies still facing many difficulties at her work like cultural heritages that do not accept the woman as a leaders. In this paper we investigate on factors involving to improve the women's participation in positions of power and decision making and to illuminate some of the barriers that hinder their career development in Jordan. In this study we conclude that the personality characteristics of woman influenced negatively on the woman role to reach the leadership position. Besides that, we analyze the most important obstacles. We discussed the women's concerns when carry responsibility as a part of occupying the leadership position.
\end{abstract}

Keyword: Women’s Leadership, cultural, Personal, Training leadership, Male behavior

\section{Introduction}

The success and efficiency of leadership depends on managerial position of what leader possesses of personal characteristics, education qualification and professional expertise. These make him/her eligible and confident to make decisions and helps him/her to face situations occur between now and then. Thus, a person who controls decision needs the capabilities and desire terms to education qualifications, specialization, expertise, knowledge and solid background accompanied by social abilities in order to balance responsibilities and the social demands as the conditions of his family, social view and economic conditions. The improvement of woman leaders role, and her contribution in development are stem from the firm belief that improving the situation of Arab women working as a key pillar of the community support development and fundamental of social and developmental improvements (Al-Shiahbi, 2002).

Women's leadership value is increasing continuously in the last twenty years as a man's colleague in managing private and public sectors companies. This partnership with man created plentiful job vacancies for the highly trained and developed women in Jordan, however, the existing gap is between woman's performance in her career and sharing in decision making, especially in the high management positions (Al-Shiahbi, 2003).

\section{Background women leadership in Jordan}

The major aim of the development is to get the single person satisfied; this satisfaction can be reached by ensuring the sharing of all society members. Therefore, it is demanded to let the woman takes part in the improvement process 
strongly and totally, to show the real method out, that is to get accomplishment in the highly developed societies where the merit, unrestricted markets and the giant companies will determine the dominance (Ramzi, 2002, and Asskar, 2003).

According to Tripp (2003) the proportion of women in positions of power and decision making remains very low worldwide, compared to that of men. The participation of women represents less than 35\% of most countries' leadership, yet they are estimated to comprise more than half of the world's population (McCormick Higgins, 2005).

The study was done by Yang (1998) deciphers the great difference in woman's percentage on the top management positions regarding to working woman's percentage in the high developed countries. The ratios in United States are $3 \%$ of the high managerial positions were filled by woman where $40 \%$ of the workers are women. This inequality also appeared in the Arabic societies tremendously for all managerial positions (Al-Shihabi, 2001).

Although there is quick growth in the economic activities that are done by Arab woman, it is the lowest in the world. In the Arabic regions just $29 \%$ of the total labor market is the woman taking part; although the rate of $39 \%$ in similar countries in terms of income. It is the highest in North African Arab countries like Morocco and Tunisia, where it's lower in Jordan compared to any other Arab country (Nusseir, 2003).

In 2003 the Jordanian human resources indicated that the percentage of female students involved in the high educational level inside Jordan is $50.4 \%$; and the female students' percentage in all educational levels is $49.4 \%$. The illiteracy percentage among females more than 15 years old is reduced to $15.2 \%$, and Jordanian woman's percentage that are participating in the real economic activity is $6.7 \%$. The unemployed women's percentage is $19.3 \%$ and the $44.8 \%$ for the employed women's percentage in the field of the civil service out of the whole number of the employees.

Per Civil Services Bureau statistics in 2004 regarding to the minister's position occupation in Jordan the first female minister was in 1993, this female minister filled the Ministry of Industry and Trading. Regarding to other high positions occupation a female had been assigned for managerial ruler, estimated percentage is $1 \%$ in the municipal council and rural. The first woman to be assigned in the judiciary field was in 1996. In general, female’s participation percentage in the high level in the civil service is $3.18 \%$, in the first level is $11 \%$; in manager position is $7.5 \%$ and the administrative employs is $11.6 \%$.

The governmental support for Jordanian working women appeared obviously by the gradual increment in the percentages of the women position's occupation. For example, in general (private and public sectors) the percentage jumped to $46.4 \%$ in private sector in 2006 and to $48 \%$ in the public one for the same year. The percentage also increased from $2.3 \% 1990$ to $16.5 \%$ in 2006 for the diplomatic corps. Currently the percentage of women in the senate council (Jordanian parliament) is 12.1 where it was 2.3\% in 1990; on the other council (parliament) it is now 5.8\% where it was zero in 1990. This is for the public sector where in the private one the percentage for women who running their own business increased from $6.8 \%$ in 2000 to $10 \%$ in 2005, all the mentioned percentages are per the Jordanian Statistics Department in 2008. This study aims to identify the important factors that have significant effect on women leadership in Jordan.

\section{Factors affect Women's occupy to Leadership}

Lowe-Morna (2000) indicated that factors contributing to low representation of women in leadership positions originate from social, personal, Training leadership and Male behavior top management. On other hand, Verba, Burns, and Schlozman (1997) suggested that low participation of women in leadership is due to women's limited political and leadership engagement in activities. Verba et al. (1997), indicated women are less politically interested, less informed, and less efficient than men. These factors contribute to their inadequate representation in higher leadership. On the opposite, Dow (2001) indicated that women have the ambition and interest to participate in leadership, but they are insufficiently represented in leadership positions because of their socialization and cultural role expectations.

\subsection{Social cultural Factors}

Society directed women away from positions of power and decision making beginning in childhood, because women from an early age were not trained to be leaders Dow (2001). According to Tripp (2003), in many societies, girls are confined to their home where they are taught to accept orders from everybody, including brothers. The fact that women are expected to accept men's decisions without question transfers from household to social and political environments where men continue to be the decision makers.

In addition, girls tend to lack the confidence and skills necessary for leadership due to earlier minimal access to education and training (Ntseane, 2002). In most Arabic, Western and African cultures, boys are exposed to masculine behaviors and activities since they are young; they are taught to be strong, aggressive, and outspoken, while girls are taught to be passive, soft-spoken, and compliant. 
A problem faced by women aspiring to leadership might be of behavioral double-binds, in which society's expectation or perception is that, for a woman to be an effective leader she should exhibit masculine behavior, such as tough and authoritative. However, when women exhibit such behaviors, they are portrayed as misfits.

Woman facing at her work many of the impediments with social characteristics, like the traditions, habits, cultural heritages and social value that don't accept the woman as a leader or as the head of group of man(Badawood, 2002).

The cultural inheritance and the social standards the negative social view to the woman's work considers one of the basic impediments that put the woman far from the leadership positions, as the values, traditions, and the habits encourage the woman on simple routine works, while leaving the big works with responsibility (leadership) to the man as more capable than the woman. Society still look at the woman in the works field an un-equally with the look toward the man, as well treating the woman as an integrating element; not as an active or basic element in building the society (Ramzi, 2002).

The different mass media that contribute in introducing and enhancing the traditional picture of the woman that follow the man and consuming cosmetics and perfumes, and its reluctance to introduce pictures are models about the successful woman leaders in different fields (Al-Ibrahim, 2008).

A factor that researchers have written much about as contributing to low representation of women in higher leadership positions is the glass ceiling. It refers to the invisible barrier which prevents women from advancing into senior and executive management positions within organizations (Murrell \& James, 2001).

\subsection{Personal Factors}

Many personal aspects will be taken into considerations in order to determine the actions of a person in a leadership role. Perceptions, motivations, personality, skills, knowledge, experience, confidence, attitudes, and commitment are a few of the variables which are important for understanding the behavior of people at work, whether they are leaders or not (George \& Janes, 2000).

Personality comprises the characteristics which are related to morality and ethics (Saros, Cooper \& Hartican, 2005). Max Weber (cited in Abdullah, Abu \& Samer, 2008) defines three stages of characteristics of leaders, in which first stage is the identification of leaders personality; second stage focuses on the behaviors of leaders; and the last stage focuses more on leaders' style and the situation they face.

There are many differences in terms of points of view regarding the woman's right to occupy the advanced leadership position. Question as to what support the woman's right to occupy this position has also been asked. Apart from that opinions on the equality of women with men, and some opinions that consider women as less capable in the performance and need continuous supervision and monitoring; have been voiced out. Despite all these numerous questions and opinions, what are actually apparent here the differences between the woman and the man at work (Al-shehabi, 2001). still there are personal impediments related to the woman's herself that lead to limiting her from reaching the leadership positions, of the most important impediments such as lack of self confidence, the traditional social raising that concentrates on the woman's dependency on other the father, husband and brother) in more of her affairs made her personality negative and depending on other. She is more than worried to carry the responsibility as a result of occupying the leadership position, hence losing trust in her self-confidence and trust in her capability to make the decisions and to carry the responsibility (Al-Shehabi, 2001).

The woman is facing the problem functional duality, since the woman performs the influential and important role towards the family and the house, and this imposes on her the secondary role in the functional field, as the family order changed as a result of the woman going out to work, and her roles became multiple and crowded responsibilities (Al-Halwani, 2002).

Decline in woman's productivity in some stages of her functional life as a result of being far from work and training for long periods of time in order to perform her role as a wife and mother, and the lack of recognizing the woman's productivity in those social roles that push the work's owner to prefer men's work on women (Badawood, 2002).

\subsection{Women Training leadership}

Greenberg (2001) lists four major principles for the effectiveness of employee training, which include participations, (where the participant gives a commitment and learns more quickly), transfer of training, repetition, and feedback. These principles can be applied in training of leadership to build self- confidence.

Allio (2009) said leadership can be enhanced through training. Robert Thomas (cited in Allio, 2009) discussed about pragmatic approach in developing leaders. According to him, the approach includes careful selection, job training and lastly careful mentoring. Kouzes and Posner (cited in Abdullah et al., 2008) state that leadership is not about position, but it is more on matters such as the practice and behaviors as a leader. 
The Woman suffers from several problems and training impediments that limit her to occupy leadership positions, whether if she is the developing or developed environment, since those impediments play the negative prominent and effecting rule on the woman's performance at work, and of the most important impediments are the following:

The woman's limited qualifications, the administrative and functional experiences. The leadership position needs the presence of several qualifications and experiences for the one who seeks to occupy it in order to succeed in the leadership work, so the absence of those qualifications and experiences in the working woman reduce her opportunity to occupy those positions (Al-Shehabi, 2001).

One of the reasons for the absence of those qualifications is the social attitudes in determining the capabilities types that the woman could acquire (Al-Ghanem, 1999), in addition to binding the administrative competency only in men, and skepticisms in the woman's capabilities that reaches the leadership position (Badawood, 2002).

Lack of education and employment opportunity Education and employment experience are necessary for women's career advancement and consideration for leadership (Conway, 2001). Most women who run for office have higher level of education and work or professional experience. Conway (2001) indicated that social norms, combined with limited education and occupational opportunities, may prevent women from obtaining the necessary skills and resources to compete successfully with men for leadership positions.

\subsection{Top management male behavior}

Women's oppression is part of the male behavior of the top management. It indicates women's under representation. It is important to relate to the existence of women's oppression and marginalization. Feminism is a struggle that exists to end oppression. It exists to benefit all women, regardless of group, class, or race; it is not a privilege of women over men, but rather a meaningful power, used to change people's lives.

Literature has indicated that social, economic, and political structures provide men with power to dominate and oppress women (Dow, 2001; Tripp, 2003). (Marshall 1997) indicated that feminism may frame women's research in leadership positions to expand leadership theory; power and politics. As women in Jordan have been and continue to be under men's dominance, feminism might help women understand and share experiences with other women and remove discrimination against women in occupying the top management positions.

In term of structural explanation some theorists have attributed power differences to organizational structure. They argue that organizational opportunities and informal power are served to exclude women. Kanter (1977) referred to these structures as informal circles of power and powerlessness that influence the distribution of opportunities and resources for people in an organization.

\subsubsection{Discrimination}

Unfortunately, women today are still paid less than men. Even though they have similar jobs, education, skills and experience, Functional theory helps to explain why there is discrimination of women in the workplace and why it has lasted as long as it has. Society is based on stability and the cooperation of its parts to maintain that stability. Because of the ancient tradition of women staying home while their husbands go out to work, women's role according to the society is housekeeper. The society has to make changes elsewhere - for instance recognizing the equality of women in the workforce - to compensate for these changes in order to reach equilibrium again.

Women therefore face discriminatory barriers mainly in environments dominated by men and male with the evaluators. Because higher levels of authority and higher wages are concentrated in such environments and are controlled primarily by men, that damage has serious consequences for women Promotion (Eagly et al. 2003).

Al-Barak (2005) indicated that the marginalization of women in national leadership positions can be traced back to the patriarchal culture of Jordan society which excluded women from leadership and men were entrusted with power to control not only their households but the economic and political environments as well.

The discrimination theories are theories based on information asymmetries and statistical discrimination. Imprecise knowledge about the productivity of young women or their career preferences may lead to systematic underestimation of the productivity of this group. The consequence is that women end up in flatter career profiles and are observed to have lower wages than their male peers. Milgrom and Oster (1987) formalized the classical economic discrimination theories model on firm promotion. They assume that individuals belonging to a minority group often have invisible abilities.

\subsubsection{Mentoring}

The mentoring relationship is a special relationship built on trust, targeted development and encouragement. A mentor is a teacher, coach, and advisor who provide guidance and opportunities for learning and professional growth to another employee. By participating in a mentor relationship, mentors develop valuable skills that can further their 
personal and professional development as well. The relationship between mentors requires honesty, commitment, openness, and effort by both individuals. In this dynamic relationship, an older and more experienced member of the organization helps the younger employee learn to navigate in the workplace (Kram, 1983).

As women's participation in leadership continues to be a subject of concern, it is necessary to consider mentoring as a tool that could promote women's career advancement. According to Noe (1988), mentoring has facilitated men's advancement for a long time, yet for women's development, mentoring benefits are not clearly defined. Mentoring was included in this study as a tool that could enhance women's development and increase their opportunities to acquire leadership positions.

Mentoring can be used as an aid to increase women's participation in positions of power and decision making and to illuminate some of the barriers that retard their career developments (Willems \& Smet, 2007). Studies little mentoring in Jordan were, making it difficult to find information on programs that might already exist.

Lack of Mentors Wellington (2003) indicated that lack of mentoring opportunities can be a barrier to women's advancement. (Broussard \& Bell 2005; Ragins, 1999) claim that mentoring could help women to overcome barriers to advancement and into higher leadership positions whether formal or informal, short- or long-term.

\subsubsection{Empowerment}

Empowerment was included in this study as a concept that can bring social and political change for women. According to Perkins \& Zimmerman (1995), powerlessness is a process that empowers the entire community of women. Through identifying and addressing issues that cause others to be powerless in the community, the entire community is empowered. Through empowerment, more women could gain control of their lives and democratic participation in leadership (Rappaport, 1995). Empowerment programs that are geared towards intervention may help eradicate gender issues and provide opportunities to develop knowledge and skills to women aspiring to leadership.

Gilika (2009) said there is a need of special organizations that will be responsible for the empowerment of women and urged them to open access to leadership and make the empowerment of women as a national priority. Jordanian women could benefit from empowerment programs commenced by both private and public institutions as it could provide positive experiences in leadership.

\section{Conclusion}

In this paper we can conclude that there are many factors involving to improve the women's participation in positions of power and decision making and to illuminate some of the barriers that hinder their career developments. The women's leadership value is become more essential in the civilized societies nowadays as a man's colleague in managing private and public sectors companies.

This partnership with man created plentiful job vacancies for the highly trained and developed women in Jordan. However, woman in some societies still facing many difficulties at her work like the traditions, habits, cultural heritages and social value that do not accept the woman as a leader or as the head of group of man. Also, the cultural inheritance and the social standards influenced negatively on the woman leadership. Further, this study can conclude that the personality characteristics of woman influenced negatively on the woman role to reach the leadership position. This study found the most important obstacles lacks of self-confidence and the traditional social. Moreover, women's always concerned to carry any responsibility as a result of occupying the leadership position. Another negative factor, the women always under men's dominance impact on the inequality of women leadership with their counterpart.

The Jordanian government has greatly support the leadership of women in all aspects of life such as, political, social and scientific. This support obviously appeared by the gradual increment in the percentages of the women position's occupation. Lastly, the empowerment programs conducted by the private and public institutions improved the skills and the experience of woman's leadership in Jordan.

\section{References}

A.Shihabi, Inaam, Azzam, \& Abdul Majid. (2003). Directions of Jordanian women's leadership in Jordan shoved constraints and women's access to senior leadership positions. Jordan Journal of Applied Sciences, 6, 96-114

A. Shihabi. (2002). Women in decision-making. Research Presented to a Conference of Women in Decision-making. Baghdad, Iraq

A. Shihabi. (1998). Women and leadership position. Central Federation of Iraq Women, Baghdad, Iraq

A. Shihabi. (2001). Woman's leadership position occupation problems from the women leadership point of view. The Iraqi's experience, the second Arabian conference of Management, the Arabian Organization of the managerial development, Committee of Arab Countries, Cairo, Egypt 
A. Asskar. (2003). Attitude towards taking the women to supervisory functions of different organizations working in Kuwaiti society. The Journal of Social Science, 31, 4

Abdullah M., AbuTineh, Samer A. Khasawneh \& Aieman A. AlOmmari. (2008). Kouzes and poser's transformational leadership model in practice: the case of Jordanian Scholl. Journal of leadership \& organization development, 29, 648-660

Al Halawani \& Abtsam. (2002). Obstacles that stand in the way of working women and impede the progress of its success, Arab Journal of Management, 22, 61- 114

AL-Ghanem Kaltham. (1999). Women and development in the Qatari society, Journal of Gulf Studies and the Arabian Peninsula and the University of Kuwait, 95

AL-Barak, Majed Lafi. (2005). The Effect of so dial, organizational and personal obstacles on the Jordanian woman to occupy leading positions. Unpublished master thesis, Mu’ta University AL- Karak, Jordan.

Al-Ibraheem Fadia. (2008). Reality of the Jordanian woman occupying leading positions at the banks. Comparative study between some the local and international banks, Unpublished master thesis, University of Jordan, Amman Jordan.

Allio R. J. (2009). Leadership the five big ideas. Journal of strategy \& leadership, 37(2),4-12

Badawood Takred. (2002). The role of the Arab organization for administrative development, the role of women in management and leadership in the Arab community, a seminar the role of women in management in the region and the Gulf, Doha, Qatar, October 2002.

Broussard, C. J., \& Bell, A. (2005). From Cinderella to CEO: How to master 10 lessons of fairy tales to transform your work life. Hoboken, NJ: Wiley.

Civil Service Bureau. (2004). The Statistical Bulliten, the Fourth Quarter, Amman, Jordan.

Department of Statistics. (2004). The Annual Statistical Book”, Amman, Jordan.

Department of Statistics. (2007), Department of Social Gender statistics, Amman, Jordan.

Department of Statistics. (2008). Man and Woman in Jordan in term of numbers”, Amman, Jordan.

Department of Statistics. (2009). Man and Woman in Jordan in term of numbers”, Amman, Jordan.

DOS. (2007). The Department of Statistics. www.dos.gov.jo

Dow U. (2001). How the global informs the local: The Botswana citizenship case. Health Care for Women International, 22, 319-331. doi:10.1080/07399330120965, http://dx.doi.org/10.1080/07399330120965

Eagly, A. H., Johannesen-Schmidt, R. B., \& van Engen, M. L. (2003). Transformational, transactional, and laissez-faire leadership styles: A meta-analysis comparing women and men. Psychological Bulletin, 129(4), 569-591. Retrieved May 22, 2005, from EBSCOhost database. doi:10.1037/0033-2909.129.4.569, http://dx.doi.org/10.1037/0033-2909.129.4.569

George, J.M.Jones, G.R. (2000). Essential of management organizational behavior. united state of America : prentice hill.

Gilike M. M. (2009). Lived experiences of Batswana in national leadership position : a doctor of philosophy thesis , Capella University, Minneapolis, USA, 2009

Greebberg, J. (2001). Managing behavior in organizations . united state of America : prentice hill

Kanter, R. M. (1977). Men and women of corporation. New York: Basic Books.

Kram, K. E. (1983). Phases of the mentor relationship. A cademy of Management Journal, 26, 608-625.

Lowe-Morna, C. (2000). Women's political participation in SADC. Paper presented at the International Institute for Democracy and Electoral Assistance (IDEA) Conference, Gaborone. Retrieved May 12, 2006, from http://www.idea.int/archive/botswana.cfm

Marshall, C. (1997). Feminist critical policy analysis: A perspective from primary and secondary schooling. London: Falmer Press.

McCormick Higgins, J. A. (2005). Finding our way: Women's lived experiences leading to the legislatures of Pennsylvania and Maryland. Unpublished doctoral dissertation, Pennsylvania State University, University Park.

Milgrom P. \& S. Oster. (1987). Job Discrimination, market forces, and the invisibility hypothesis, Quarterly Journal of Economics, 102:453-476. doi:10.2307/1884213, http://dx.doi.org/0.2307/1884213 
Ministry of higher education and scientific research http://www.mohe.gov.jo, 1 Apr, 2010, 5.30 pm.

Murrell, A. J., \& James, E. H. (2001). Gender and diversity in organizations: Past, present and future directions. Sex Roles, 45(5-6), 243-257. doi:10.1023/A:1014393312588, http://dx.doi.org/10.1023/A:1014393312588

Nassar, Heba, (2003). The role of women in managerial positions in some parts of the Arab community and the role of States and Governments in activating the role of women in management, the a symposium role of women in management in the Gulf region, Doha,

Noe, R. A. (1988). Women and mentoring: A review and research agenda. Academy of Management Review, 13(1), 65-78.

Ntseane, P. G. (2002). A Botswana's rural transition to urban business success: Collective struggles, collective learning. University of Botswana.

Perkins, D. D., \& Zimmerman, M. A. (1995). Empowerment theory, research, and application. American Journal of Community Psychology, 23(5), 569-579. doi:10.1007/BF02506982, http://dx.doi.org/10.1007/BF02506982

Ragins, B. R., \& Cotton, J. L. (1999). Mentoring functions and outcomes: A comparison of men and women in formal and informal mentoring relationships. Journal of Applied Psychology, 84(4), 529-550. doi:10.1037/0021-9010.84.4.529, http://dx.doi.org/10.1037/0021-9010.84.4.529

Ramzi ,N. (2002). Arab women and work, reality and prospects”, A study of three Arabian Societies, the Journal of Social Science, 30, 3

Rappaport, J. (1995). Empowerment meets narrative: Listening to stories and creating settings. American Journal of Community Psychology, 23(5), 795-807. doi:10.1007/BF02506992, http://dx.doi.org/10.1007/BF02506992

Sarros, J.C., Cooper, B. K. \& Hartican, A. M. (2005). Leadership and character . Journal of leadership\& organization development, 27(8), 682-699.

The official website of the Jordanian Ministry of Culture, Accessed in 10-Dec-2009, http://www.culture.gov.jo/index.php?option=com_content\&view=article\&id=31\&Item=67\&lang=ar.

Tripp, A. M. (2001). The new political activism in Africa. Journal of Democracy, 12(3), 131-155. doi:10.1353/jod.2001.0060, http://dx.doi.org/10.1353/jod.2001.0060

Tripp, A. M. (2003). Women in movement: Transformations in African political landscapes. International Feminist Journal of Politics, 5(2), 233-255. doi:10.1080/1461674032000080585, http://dx.doi.org/10.1080/1461674032000080585

Verba, S., Burns, N., \& Schlozman, K. L. (1997). Knowing and caring about politics: Gender and political engagement. The Journal of Politics, 59(4), 1057-1072. doi:10.2307/2998592, http://dx.doi.org/10.2307/2998592

Wellington, S. W. (2003). Making the case: Women in law. In D. L. Rhode (Ed.), The difference "difference” makes: Women and leadership (pp. 90-97). Stanford, CA: Stanford University Press.

Willems, H., \& Smet, M. (2007). Mentoring driving diversity. Organization Development Journal, 25(2), 107.

Yang, Nini. (1998). An international perspective on socioeconomic changes and their affection life stress and career success of working women, sam advanced management journal, 63(3) 